\section{FOOD AND PREGNANCY}

$\mathrm{T}$

HE average human baby weighs between $7 \mathrm{lb}$. and $8 \mathrm{lb}$. at birth; it contains about $370 \mathrm{gm}$. of protein, $25 \mathrm{gm}$. of calcium, $14 \mathrm{gm}$. of phosphorus and $0.4 \mathrm{gm}$. of iron. It builds up two thirds or more of these materials during the last three months before birth. All this material must come from the mother. Two questions arise. First, how is the transfer of the necessary material to the fotus regulated ? Secondly, how far does the health of the baby and mother depend on the mother's supply of food ? These two questions occupied the English Group of the Nutrition Society at its meeting on February 6.

Food passes from the circulation of the mother to that of the fotus through the placenta. This passage is not a free diffusion. Sir Joseph Barcroft discussed the placenta as a barrier. New information has been obtained by the use of heavy sodium. The guinea pig foetus comes within 10 per cent of equilibrium with heavy sodium in the maternal plasma in 5-7 hours; the extracellular fluid of the mother comes within 10 per cent of equilibrium in about 5 minutes. It is possible to calculate the diffusion coefficient of oxygen across the placenta. About $0.1 \mathrm{ml}$. of oxygen passes from the blood of a ewe to her foetus per square centimetre per second, when the difference between the pressure of oxygen in the blood of mother and fotus is $1 \mathrm{~mm}$. of mercury. Across other body barriers the diffusion coefficient is about fifty times as great. As the time of birth approaches, it becomes difficult to keep up a passage of oxygen through the placenta rapid enough to meet the needs of the fœtus.

The placenta may exercise a selective effect. According to Dr. Hoch, who spoke after Sir Joseph, the concentration of vitamin $A$ in the plasma of mother and baby, at birth, is about equal; but the concentration of carotene is much higher in the mother's plasma.

The degree of obstruction by the placenta is reduced by mechanical means. Corrugation increases the area of the surface of interchange and the vessels of the fœtal and maternal circulation run in opposite directions. The hæmoglobin of the foetus has a higher affinity for oxygen at low tension than has that of the mother. The hydrogen ion concentration of the blood of a pregnant ewe is raised; in consequence, the hæmoglobin of her blood gives up oxygen at abnormally high tensions.

The relative growth-rate of a goat foetus, at different periods of pregnancy, is related to the rate of transfer of heavy sodium per unit weight of foetus through the placenta. Hence, the rate of growth of the foetus may be determined by the rate of passage of food through the placenta, and therefore by the size and vascularity of the placenta.

Dr. John Hammond suggested that the partition of food between foetus and mother is regulated by the same factors as regulate the partition between different maternal tissues ; that is, the fœetus, with a very high metabolic rate, competes with maternal tissues at a level slightly below that of the mother's central nervous system. The rate of growth is limited in some way by the mother. A foal, born of a Shetland pony mare inseminated from a Shire stallion, is smaller at birth and remains small until weaned. It is only when it eats according to appetite that genetic factors cause it to grow faster. The rate of growth, in utero, may be determined either by the rate of supply of food through the placenta, as suggested by Barcroft, or by the supply of an internal secretion or a metabolic substance produced by the mother.

The relation of growth to the supply of food to the fœetus becomes important in human pregnancy. The baby of a diabetic mother is fat, owing to the large amount of sugar supplied to it. Mr. Aleck Bourne, discussing fotal development, stated that a large proportion of deaths in utero are due to smallness or ill-development of the placenta, and suggested that lack of vigour after birth may be due to undernutrition of the fœtus before birth.

How much, then, do the health of mother and offspring depend on the food supply of the mother ? Lambs may be lost through neglect of the feeding of ewes in the late stages of pregnancy. But species differ, and the human mother is sacrificed to a much greater degree to the welfare of her offspring. Prof. A. St.G. Huggett said that he recognized five degrees of undernutrition of the mother; only in the most severe is the health of the baby affected. At one time the occurrence of fotal rickets was disputed; however, it is found associated with osteomalacia of the mother, and the foetus may suffer from keratomalacia if the supply of vitamin A to the mother is grossly inadequate. In the more severe degrees of under-nutrition, it may need four years of supplementary feeding to bring the baby back to normal, or it may never catch up completely.

Such catastrophes are seen only in extreme cases, but it might be expected that the health of the mother would suffer as the result of less severe degrees of undernutrition, even if the baby escapes. Apart from supplying the materials used by the foetus, she has to provide some $300 \mathrm{gm}$. of protein for the development of the uterus and other reproductive apparatus; if the protein is not provided by her food, over and above her normal needs, it must come from other tissues. Pregnant women are known to suffer more than others when food is short. They may get osteomalacia, owing to lack of calcium and vitamin $D$; frank night blindness occurs during pregnancy in Newfoundland, for example, and clears up afterwards; in a large proportion of cases of beriberi in women the disease appears to have been brought on by pregnancy. We have laboratory evidence which appears to show that deficiencies of vitamins $A, B$, and $C$ are more common among pregnant women eating their customary diets than among other women. For example, Dr. Hoch reported that he has found the levels of vitamin A in the plasma of pregnant women to be unusually low.

We come back to the old question of the intermediate states of deficiency. As Szent-Györgi has put it: How do we know that they are healthy, just because they have no scurvy? McCance and his colleagues collected records of the diets of pregnant women. The standard was so low, on the whole, and deteriorated so strikingly with fall of income, that it might be expected that there would be plenty of evidence of the ill-effects of undernutrition among poorer mothers. Mr. R. M. Titmuss, who discussed the relation of stillbirth and neonatal mortality to various influences, quoted the report of the Registrar General ; the death-rate of babies, in the first month after birth, ranges from 22 per 1,000 in Class I to 33 in Class V. However, he showed that this issue is confused by. many factors; for example, the degree of antenatal care, and the age of the mother, which is lower, on the average, in the poorer classes. 
The frequency of stillbirth in England and Wales has remained practically unchanged since 1927, and mortality in the first month fell by only one quarter during the period from 1906 -10 to 1937 ; whereas the mortality during the remaining eleven months of the first year of life fell by more than 60 per cent during the same period. Dr. I. Leitch, who followed Mr. Titmuss, suggested that, again, the results are complicated by improvement in antenatal care; more subnormal babies now survive to be born subnormal and die during the first month. The final value of any factor can only be assessed from the final results of the whole course of pregnancy and the early months of the baby's life. So many factors are involved that records of the distribution of deaths associated with pregnancy according to class, locality or time are not likely to give clear evidence of the effects of the single factor, nutrition.

There has been much unsound generalization about the effects of diet on the health of the mother. One may quote the instance of ketosis of ewes, which has been ascribed to overfeeding and lack of exercise. Here it was possible to make a clean experiment and Fraser, at the Rowett Institute, showed that ketosis did not occur in overfed sheep, but could be produced by underfeeding and cured by giving more food. Many still ascribe the rarity of eclampsia in Germany during the War of 1914-18 to the reduction of the amount of meat eaten. But the incidence of eclampsia rose immediately after the War ended, while the consumption of meat remained low. It would be more justifiable to give the credit for the reduction to the increased consumption of vitamin $B_{1}$, due to the higher extraction of grain during the war years. But it is now claimed that the changes were due to the fall in the number of first pregnancies during the war years. Eclampsia occurs more often in first than in later pregnancies.

There is one clear-cut instance of a deterioration of health of mother and infant due to deficiency of a nutrient in the ordinary diet. This nutrient is iron. In this instance, we have the specific evidence of iron deficiency, anæmia, and the unmistakable improvement when iron is administered. Mr. Aleck Bourne and Prof. Huggett both quoted three recent experimental studies of the effect of improvements of diet in other respects on the health of mother and baby: the Birthday Trust, the People's League of Health and the Toronto experiments. In these experiments the amount and quality of the foods supplied differed widely. In the Birthday Trust experiment, which was reported at this meeting by Lady Balfour, the extra food provided about $7 \mathrm{gm}$. animal protein, $0.35 \mathrm{gm}$. calcium, $0.3 \mathrm{gm}$. iron and, to those who were given yeast or Marmite, some 240 I.U. vitamin $B_{1}$. McCance and his colleagues measured the diets of twenty-five of the women who were receiving this extra food; the average amounts eaten per day were $36 \mathrm{gm}$. animal protein, $0.59 \mathrm{gm}$. calcium and $11.0 \mathrm{mgm}$. iron; it appears that the women either did not themselves eat all the extra food allowed to them or ate less of other foods, such as meat, when they were given this extra food. In the People's League of Health experiment the basic diets were probably better; large amounts of iron and moderate amounts of calcium and vitamin $B_{1}$ were given and the intake of vitamins $A, D$ and ascorbic acid was raised well above the average. As these supplements appeared in the form of a 'medicine', they were in all probability consumed entirely by the recipient and not distributed among the family. In the Toronto experiment the diet was raised to a satisfactory level in every particular. In the Birthday Trust experiment, as reported by Lady Balfour, the frequency of stillbirths and deaths during the first month of the baby's life was reduced. In the People's League of Health the incidence of toxæmia (precisely defined) and of premature birth were lower in the supplemented than in the control group. In the Toronto experiment the number of subjects was small and the study more detailed; the chief significance of this experiment lies in the improvement of the subjects, as assessed clinically by an observer who did not know which of the subjects received the food supplements, and in the increase in the number who remained free from any complications. Also, the frequency of anæmia, toxæmia, threatened miscarriage, actual miscarriage, premature birth, endometritis, mastitis and breast abscess was less in the supplemented group, and the average duration of labour shorter; but as the numbers were small, the reduction in the frequency of any of these accidents may not be significant.

These three studies illustrate the difficulties that arise in this type of experiment. In the People's League of Health experiment the incidence of toxæmia was considerably higher in first than in later pregnancies. In the Birthday Trust experiment first pregnancies were more common in the control than in the supplemented group. In fact, Lady Balfour's report was largely devoted to the disentanglement of the confusing factors which might vitiate the results. When attention is focused on accidents, which occur in a small proportion only of the subjects, the results are not significant unless large numbers are studied; when large numbers are studied, it is difficult to control the diet and other interfering factors; and these accidents are, probably, not directly due to inadequacy of the diet. It would be better if it were possible to measure some feature that is present in all cases. Mr. Bourne suggested one; he said that obstetricians want to see 'vigorous' babies, and gave the ability to recover birth weight in ten days as one criterion of 'vigour'. This rate of recovery of weight could be measured.

The general well-being of the mother should be considered. According to Mr. Titmuss, one out of every eight pregnancies does not produce a baby alive at the end of one year. The attention of obstetricians is focused on the various catastrophes that happen between conception and the end of the first few months or less of the baby's life. But, socially, it is more important that seven mothers should be happy and feel well than that the eighth baby should survive. Is it impossible to devise some method of assessing well rbeing? It should at least be possible to compare the physical state of women before pregnancy with that, say, twelve months after delivery. This well-being may be unrelated to nutrition; but we ought to know.

In any future experiment it would be advisable either to raise the standard of the diet to a satisfactory level in every particular or to raise the intake of one constituent only; blunderbuss administration of a mixture of vitamins and minerals is unlikely to give clear results. Uniform criteria of, for example, prematurity should be adopted, and uniform methods of measurement fixed. At present, however, gigantic dietetic experiments are in progress. Prof. Huggett discussed the changes in diet due to rationing. As pointed out by Prof. J. R. Marrack, the supply of milk free or at a reduced 
price and the provision of cod liver oil and fruit juice have raised the general level of the diet of pregnant women above the average which existed before the War. Diets are now more uniform. A survey of the nutritional status and health of pregnant women now should give useful information on their reactions to standard conditions, and a comparison with pre-war records would indicate the effects of certain changes in diet.

We need to know more about the physiology of pregnancy. Why is it that a woman appears to need extra supplies of vitamins $A, B_{1}$ and $C$ during pregnancy? What is the purpose of the extra store of protein that is accumulated by a pregnant animal ? Why, as Dr. T. Moore pointed out, has a baby, at birth, such a low stock of vitamin A ? When we can answer these questions, we shall be in a better position to know what clinical evidences of deficiency we should look for and to lay down the food requirements of pregnancy. Prof. Huggett gave personal estimates of the levels to which the diet of a pregnant woman should be raised: $1-1.5 \mathrm{gm}$. of protein per $\mathrm{kgm}$. of body weight, $1-1.5$ of calcium and phosphorus, increased amounts of vitamins, particularly $A, B_{1}$ and D ; supplements of iron; in terms of actual food-stuffs, more cheese, milk, vegetables and fruit. Until we have better knowledge of the physiology of pregnancy and more detailed evidence of the effects of diet on the health of mother and baby, we cannot assess the relative urgency of these demands. But pregnant women form such a small fraction of the total population and their health is of such importance, that they should, for the present, be given the benefit of any doubt and be allowed a prior claim on our food supply.

\section{TRAWLING AND THE STOCKS OF FISH}

TN a paper read before the Royal Society of Arts 1 on January 27 on "Trawling and the Stocks of Fish", Dr. E. S. Russell, director of fishery investigations, Ministry of Agriculture and Fisheries, brought out in a convincing manner the problems which will confront us after the War in connexion with the national fish stocks of Great Britain and those of our near neighbours. In a summary of the history of the trawling industry from its beginning rather more than a century ago up to the present day, he traced its gradual growth. The demersal fishery, consisting of those fish living on or near the bottom, such as cod, haddock, hake, plaice and others, began with sailing boats fishing near shore. Then they ventured into the deep waters of the North Sea and, with the advent of the steam trawler and the great spread of fishing, went as far as Iceland and the Faroes, the Barents Sea and Bear Island, south of Spitsbergen. It is a tale of ever-increasing strength in boats and gear, and, running with it, an increase of fish-up to a certain point.

In 1866, a Royal Commission recommended that all restrictions on deep-sea fishing should be swept away and the industry allowed complete freedom of development-a measure which favoured enormously the later expansion of the trawl fisheries. It is a different matter nowadays. During the period of expansion there has been an almost continuous increase in the size and power of the steam trawler and in its fishing quality. It is a case of continued exploitation of the stocks of fish, beginning in a small way on grounds nearest at hand and spreading to all waters within reach, made possible by technical improvements in ships and gear and the building up of the fishing fleets in ever-growing strength.

The stocks of fish are not unlimited. The intense fishing made inroads into these stocks which are shown in the detailed statistics available, some of which were quoted by Dr. Russell. Those from the beginning of the century show a marked increase in the quantity of fish landed from 1886 to 1907 ; then follows a period of stabilization. With less fishing, landings necessarily fell heavily in the war period during 1914-18, in 1919-20 recovered to a level rather higher than pre-war, and in 1928 were not very different from 1907-13. Then comes a time when there is a sign of over-fishing. The landings fall off notwithstanding improvements in gear, and the average size of the fish is less. In spite of the fact that the war years had made it possible for the fish to recuperate, the very intense fishing which came after had made inroads on the stocks which could not be balanced. The only exception to the diminution of the stock was the cod in the extreme north. Here the fish were so unusually abundant, owing to changed hydrographical conditions, that this fishery itself was obliged to exercise restriction. Apart from the cod, the density of all the important demersal fish was steadily diminishing. Over-fishing was elearly the cause. The fish were not allowed to grow up.

At this point the present War broke out: once again, far fewer vessels are engaged in the fishery, once again the fish have recuperated and have grown to their full size and strength. After the War of 1914-18, enough was not known of the causes of these diminishing stocks. Modern research gives us no such excuse. As Dr. Russell states: "A con" clusion of great importance has been reached, namely, that in most fully developed fisheries a state of over-fishing has been reached, a state where the ever-increasing intensity of fishing has resulted, not in an augmentation of the catch but in a diminution". He illustrates this by the haddock statistics, but it is the same story with almost any of the other important demersal fish. He has dealt with the subject fully in his recent book, "The Over-Fishing Problem" (Cambridge, 1942).

There is a grave warning here. Already something has been done by enlarging the mesh of the nets in order that immature fish may escape, but the question of immature fish, important as it is, is not nearly so important as the question of over-fishing. Canada has already so successfully controlled her halibut fishery that it has improved enormously.

With recuperated stocks and fishing fleets greatly reduced by the ravages of war, there are now exceptional opportunities to plan a more rational exploitation of the fisheries of Great Britain, and for this it is evident that international agreement will be needed. The object of such agreement will be to secure from each fishery area the maximum steady yield that the stocks can afford-to draw the interest while leaving the capital untouched. The only cure for over-fishing is to fish less, but with our improved knowledge it is clear that proper control will bring better profit to the industry and will lead to an increase, rather than a decrease, in the amount of fish landed. 